\title{
Oral hygiene in children with epilepsy: Effect of interleukin-1 $\beta$ and VEGF levels in gingival crevicular fluid
}

\section{Higiena jamy ustnej dzieci chorych na epilepsję a stężenie interleukiny $1 \beta$ i czynnika wzrostu naczyniowo-śródbłonkowego w płynie dziąsłowym}

\author{
Gülsüm Duruk ${ }^{1, A-F}$, Hulya Aksoy ${ }^{2, A-D}$, Taskın Gurbuz ${ }^{3, A-C}$, Esra Laloglu ${ }^{4, A, B}$, Huseyin Tan ${ }^{5, A, B}$ \\ ${ }^{1}$ Inonu University, Faculty of Dentistry, Department of Pediatric Dentistry, Malatya, Turkey \\ 2 Private Medical Practice, Erzurum, Turkey \\ ${ }^{3}$ Ataturk University, Faculty of Dentistry, Department of Pediatric Dentistry, Erzurum, Turkey \\ ${ }^{4}$ Ataturk University, Faculty of Medicine, Department of Biochemistry, Erzurum, Turkey \\ ${ }^{5}$ Ataturk University, Faculty of Medicine, Department of Pediatric Neurology, Erzurum, Turkey \\ A - research concept and design; $B$ - collection and/or assembly of data; $C$ - data analysis and interpretation; \\ $D$ - writing the article; $E$ - critical revision of the article; $F$ - final approval of article
}

Address for correspondence

Gülsüm Duruk

E-mail: durukgulsum@yahoo.com

Conflict of interest

none declared

\section{Funding sources}

The study was funded by the Scientific Research Foundation of Ataturk University (grant 2010/140).

This study had ethical approval. The acceptance number is B.30.2. ATA .0.01.00/118.

Acknowledgments

The authors would like to thank Prof. Zekeriya Aktürk for his statistical assistance.

Received on August 29, 2016

Revised on September 27, 2016

Accepted on September 29, 2016

D0I

$10.17219 / \mathrm{dmp} / 65450$

Copyright

() 2017 by Wroclaw Medical University

and Polish Dental Society

This is an article distributed under the terms of the

Creative Commons Attribution Non-Commercial License

(http://creativecommons.org/licenses/by-nc-nd/4.0/)

\begin{abstract}
Background. The biochemical parameters in gingival crevicular fluid (GCF) are affected by some systemic diseases and poor oral hygiene.

Objectives. The aim of this study was to evaluate the total amounts of Interleukin-1 (IL-1B) and vascular endothelial growth factor (VEGF) in GCF in children with epilepsy.
\end{abstract}

Material and methods. Eighty children with epilepsy in a seizure-free period (the test group) and 80 healthy children (the control group) were evaluated. The children with epilepsy were taking valproic acid (VPA), carbamazepine, phenobarbital, and the combinations of these drugs. Gingival index (GI), plaque in$\operatorname{dex}(\mathrm{PI})$, probing depth (PD) and clinical attachment level (CAL) were measured. GCF was collected and its volume was measured. The total amounts of IL-1 $1 \beta$ and VEGF in the GCF were analyzed in the Biochemistry Laboratory at Ataturk University.

Results. The biochemical (IL-1ß and VEGF) and clinical parameters (GI, PI, PD and GCF volume) were significantly higher in children with epilepsy compared to healthy children ( $p<0.0001$ ). When the epilepsy patients were divided into groups according to the drug used in this study, there were no significant differences in the GCF levels of IL-1 3 and VEGF among the drug groups. Also, a significant gingival enlargement in the patient population was not recorded.

Conclusions. According to these results, it may be suggested that patients need optimal oral care in epilepsy.

Key words: children, epilepsy, cytokine, gingival crevicular fluid, oral health

Słowa kluczowe: dzieci, epilepsja, cytokiny, płyn dziąsłowy, higiena jamy ustnej 
The World Health Organization estimates that $0.8 \%$ of the world's population are affected by epilepsy, which is a brain disorder. ${ }^{1}$ In $35 \%$ of the cases, epilepsy is due to an identifiable central nervous system (CNS) injury, whereas in the rest of the cases, it is a result of either genetic or unknown causes. ${ }^{2}$

For preventing seizure, different drugs are used in the treatment of epilepsy. But there are some side effects of these medications. For example, in $30-50 \%$ of the cases, phenytoin develops a significant gingival overgrowth. Although the reason of the gingival overgrowth is not fully understood, some studies have shown that inflammatory cytokines and growth factors may play an important role in the pathogenesis of gingival changes. ${ }^{3,4}$

IL-1 $\beta, 17-\mathrm{kDa}$ glycoprotein is a potent proinflammatory cytokine. It is produced predominantly not only by monocytes/macrophages, but also by fibroblasts and bone cells. ${ }^{5}$ Its production may be induced by microorganisms, microbial products, inflammatory agents and antigens. ${ }^{6}$ Several clinical studies have addressed the change of IL-1 $\beta$ levels in the blood and cerebrospinal fluid (CSF) of patients with focal epilepsy. ${ }^{7,8}$ It has been found that IL- $1 \beta$ plays a role in the development of a neuronal cell death after traumatic, ischemic, excitotoxic and seizureinduced brain injuries. ${ }^{8,9}$

Gingival crevicular fluid (GCF) is an exudate that is originated from gingival crevices or periodontal pockets around teeth with inflamed gingiva. GCF contains a variety of materials, including leukocytes (mainly neutrophils), antibodies, complement proteins, various enzymes, and cytokines. ${ }^{10-12}$ Therefore, GCF component or constituent measurements are useful to show the alterations in gingival tissues. Additionally, in the oral cavity, poor oral hygiene and gingival and periodontal diseases without gingival enlargement can also modify the contents of GCF. In some studies, poor oral hygiene, gingivitis, periodontitis or a gingival injury increases IL-1 $\beta$ and VEGF values in GCF. ${ }^{13-15}$

IL-1 $\beta$ has an important role in regulating and increasing the inflammatory response in periodontal diseases. IL-1 $\beta$ levels in periodontal tissues and GCF have been closely associated with periodontal disease severity and it has been found that they significantly increase in diseased sites, compared to healthy sites. ${ }^{15}$

A vascular endothelial growth factor (VEGF), 45-kDa homodimeric glycoprotein, is an angiogenesis and vascular permeability factor that increases microvascular permeability, stimulates endothelial cell (EC) proliferation, and induces proteolytic enzyme expression and the migration of ECs, monocytes and osteoblasts, all of which are essential for angiogenesis. ${ }^{16}$

An increase in VEGF in GCF affects the periodontal vasculature profoundly during periodontal disease progression. ${ }^{13,14}$ The increased concentration of VEGF in periodontitis may be one of the reasons for the increased vascularization and permeability, and it may be consid- ered as a sign of severe periodontitis. ${ }^{13,17,18}$ VEGF is detectable in periodontal tissues within endothelial cells, plasma cells and macrophages, in junctional, sulcular and gingival epithelium, and in GCF. ${ }^{18}$ Moreover, VEGF expression may be induced by IL-6, IL-1 and PGE 2 . VEGF also appears to be regulated by the oxygen concentration that cells are exposed to, with hypoxia inducing its expression. ${ }^{19}$

In this study, we aimed to investigate the total amounts of IL-1 $\beta$ and VEGF in GCF in epileptic patients in a seizure-free period and focused on the relationship between oral hygiene and these biochemical parameters.

\section{Material and methods}

\section{Patient selection}

This study was performed in the Department of Pediatric Neurology, Faculty of Medicine and Department of Pedodontics, Faculty of Dentistry of Ataturk University in 2012. The samples were analyzed in the Biochemistry Department. A total of 160 subjects, 80 pediatric patients (36 girls, 44 boys) with epilepsy, the test group, and 80 systemically healthy children (46 girls, 34 boys), the control group, aged 4-11, participated in this study. The study was approved by the local ethics committee of the Medical School of Ataturk University and performed in accordance with good clinical practice guidelines. Informed consent was obtained from the parents of patients. Children were excluded from the study if they had any systemic diseases, periodontal diseases, dental caries or filling in the maxillary anterior teeth, and had taken antibiotics or anti-inflammatory drugs in the previous one month. The children in the test group had no other systemic diseases except epilepsy and they had had no seizures in the past month.

\section{Clinical measurements}

Periodontal examinations were carried out and recorded by the same investigator. None of the study patients had gingival overgrowth. Four points (mesio-buccal, mesio-oral, disto-buccal and disto-oral) of per maxillary anterior primary teeth were selected for clinical measurements. If there were no maxillary anterior primary teeth, permanent maxillary anterior teeth were selected. The selected teeth were caries-free and unfilled. The gingival conditions of the patients were evaluated using the Silness-Loe plaque index (PI), Loe gingival index (GI), clinical attachment loss (CAL) and probing pocket depth (PD) to the nearest millimeter with a Williams ${ }^{\circledR}$ probe (Aesculap, Inc., Center Valley, USA). ${ }^{20,21}$ The obtained scores were calculated by dividing the total score by the total number of scored surfaces. 


\section{GCF collection}

The selected tooth sites were mesiobuccal sites of maxillary central or lateral in primary or permanent dentition for collecting GCF. A total of 160 GCF samples were obtained, 80 from epilepsy patients and 80 from a healthy group. The upper anterior teeth were included in the study to improve access and to reduce the risk of salivary contamination during these processes. To avoid the blood contamination and the possible stimulation of GCF flow during clinical measurements, samples were collected before any other clinical recordings except PI. Prior to sampling, each selected site was carefully isolated using cotton rolls. A Periopaper ${ }^{\circledR}$ strip (Oraflow, Plainview, USA) was placed in the pocket until a mild resistance was felt and then left in place for $30 \mathrm{~s}$. In the case of visible contamination with blood, the strips were removed. To eliminate the risk of vaporization, the paper strips with GCF were immediately carried to a previously calibrated electronic gingival fluid measuring device (Periotron ${ }^{\circledR}$ 8000; Oraflow, Plainview, USA) for volume calculation. After the volume calculation, Periotron scores were converted from $\mathrm{mL}$ to microliters $(\mu \mathrm{L})$ via a computer conversion program. The samples were put into Eppendorf tubes in $300 \mu \mathrm{L}$ phosphate buffered saline (PBS), containing $100 \mu \mathrm{L}$ of $2 \%$ bovine serum albumin in PBS and immediately frozen at $-80^{\circ} \mathrm{C}$ until the day of the laboratory analysis.

\section{IL-1 $\beta$ and VEGF assay}

The level of IL-1 $\beta$ (eBioscience ${ }^{\circledR}$ Platinum ELISA, NY, USA) and VEGF (RayBio ${ }^{\circledR}$, NY, USA) in GCF was measured by ELISA and the analysis was performed according to the manufacturer's instructions using human recombinant standards in the Biochemistry Laboratory of Ataturk University. The results were reported in $\mathrm{pg} / \mathrm{mL}$ per sample. The sensitivity was $0.3 \mathrm{pg} / \mathrm{mL}$ for IL- $1 \beta$ ELISA while it was $10 \mathrm{pg} / \mathrm{mL}$ for VEGF ELISA. The samples with IL-1 $\beta$ levels below the limits of the assay's detectability were scored 0 . The IL- $1 \beta$ results were multiplied by the dilution factor $(\times 2)$.

The results were converted to $\mu \mathrm{L}$ by being divided by 1000. GCF volumes were added to the dilution factor and multiplied by IL-1 $\beta$ and VEGF levels.

\section{Statistical analysis}

Data analysis was performed using the statistical package SPSS 16 (2008, SPSS Inc., Chicago, USA). The results were expressed as mean \pm standard deviation. The data was firstly analyzed for normal distribution with a Kolmogorov-Smirnov test. The biochemical parameters between the groups were compared with Student's t-test, while the clinical parameters between the groups were compared with a non-parametric Mann-Whitney U test. The non-parametric Kruskall-Wallis test was used to evaluate the differences among the drug groups.
The Pearson correlation test was used to verify the correlations between the biochemical parameters, while Spearman's Rank correlation test was used between the clinical parameters. Spearman's Rank correlation test was used to evaluate the relationship between the clinical and biochemical parameters.

The qualitative non-parametric variable of CAL was not analyzed because the CAL of both healthy children and children with epilepsy was $\leq 2 \mathrm{~mm}$.

\section{Results}

In the epilepsy group, the clinical and biochemical parameters were significantly higher than in the control group ( $\mathrm{p}<0.0001$ for all) (Table 1 ).

Looking at the distribution of the drugs used in the epilepsy patients, in 46, 12, 10 and 12 of the 80 cases, they were taking valproic acid (VPA), carbamazepine, phenobarbital, and the combinations of these drugs, respectively. These patients had been using their respective drugs for at least 6 months. When the patients were divided into groups according to the drug used in this study, there were not any significant differences in the clinical and biochemical parameters among the drug groups ( $p>0.05)$.

There was a statistically significant positive correlation between total IL-1 $\beta$ and VEGF in both groups ( $\mathrm{p}<0.0001)$. Correlations between IL-1 $\beta$ and GI $(\mathrm{r}=0.292$, $\mathrm{p}=0.009), \mathrm{IL}-1 \beta$ and PI $(\mathrm{r}=0.359, \mathrm{p}=0.001)$, VEGF and GI $(\mathrm{r}=0.419, \mathrm{p}=0.0001)$, VEGF and PI $(\mathrm{r}=0.347, \mathrm{p}=0.002)$, GI and PI $(r=0.466, p=0.0001)$ and PD and GCF volume $(\mathrm{r}=0.662, \mathrm{p}=0.0001)$ were found in the healthy children. Regarding the children with epilepsy, correlations were found between IL-1 $\beta$ and GI ( $r=0.651, p=0.0001)$, IL-1 $\beta$ and PI $(r=0.481, p=0.0001)$, VEGF and GI $(r=0.635$, $\mathrm{p}=0.0001)$, VEGF and PI $(\mathrm{r}=0.534, \mathrm{p}=0.0001)$, GI and $\mathrm{PI}(\mathrm{r}=0.676, \mathrm{p}=0.0001)$ and PD and GCF volume $(\mathrm{r}=$ $=0.319, \mathrm{p}=0.004)$.

\section{Discussion}

The present study has shown that in epilepsy patients, the total amounts of IL-1 $\beta$ and VEGF in GCF were significantly higher than in healthy children. To our knowledge, this is the first report measuring GCF levels of IL-1 $\beta$ and VEGF in epilepsy patients.

In our study, all patients were taking anti-epileptic drugs in a seizure-free period. Researchers have found that IL-1 $\beta$ and VEGF production increases in the blood and brain during an epileptic seizure. ${ }^{9,22}$ Vezzani et al. reported that cytokine levels approximate to the normal values in brain tissue in the next 3-7 days after the seizure. ${ }^{7}$ In this study, an increase in biochemical parameters in GCF couldn't be attributed to the epileptic seizures because all the epilepsy cases were seizure-free. 
Table 1. The mean \pm SD of total amounts of IL-1 $\beta$ and VEGF and clinical parameters of both groups

\begin{tabular}{|l|c|c|c|c|c|}
\multicolumn{2}{c|}{ Parameters } & Healthy & Epilepsy & $p$ values* & Statistically used tests \\
\hline Biochemical parameters & total IL-1 $\beta(p g)$ & $4.02 \pm 0.89$ & $17.15 \pm 6.90$ & 0.0001 & Student's t-test \\
& total VEGF (pg) & $48.46 \pm 10.92$ & $124.06 \pm 35.57$ & 0.0001 & Mann-Whitney U test \\
Clinical parameters & GI & $0.26 \pm 0.13$ & $0.81 \pm 0.14$ & 0.0001 & 0.0001 \\
& PI & $0.35 \pm 0.20$ & $0.75 \pm 0.14$ & 0.0001 & 0.0001 \\
\hline
\end{tabular}

* The $p$ values show the comparison of the values in the same row.

Moreover, increased total amounts of IL-1 $\beta$ and VEGF in GCF may be due to some other causes in epilepsy patients. Gingival enlargement may be one of the factors that increases IL-1 $\beta$ and VEGF to damage the integrity of the gingiva. Some anti-epileptic drugs (especially phenytoin) have side effects such as gingival enlargement. This situation was found to be rare in patients taking other antiepileptic drugs such as phenobarbital, valproic acid, carbamazepine, and levetiracetam. In our study, none of the patients with epilepsy was taking phenytoin. Besides, we couldn't find significant gingival enlargement in the patient population. The authors reported that valproic acid prevented an inflammation, and carbamazepine could cause an inflammation and hepatic injury as a result of this. ${ }^{23,24}$ We couldn't find any information about possible anti-inflammatory effects of phenobarbital. But, in our study, when patients were classified according to the use of the drug, no differences were found in IL- $1 \beta$ and VEGF levels of GCF among the drug groups.

We thought that the cause of the increased total amounts of IL- $1 \beta$ and VEGF in GCF may be from different factors rather than seizure, drugs or gingival enlargement. IL- $1 \beta$ is one of the most important inflammatory cytokines in the oral cavity and plays a major role in gingivitis and periodontitis, ${ }^{15}$ while VEGF is one of the primary mediators of neovascularization in chronic inflammation, including periodontal disease and wound repair, ${ }^{25}$ and plays a major role in periodontal diseases to increase vascularization and permeability and help the passage of inflammatory cells, and it may be considered as a sign of the severity of periodontitis. , $^{8,18,19}$

There are various bacterial species embedded in a matrix of bacterial products and host-derived factors in dental biofilm or dental plaque. This biofilm can stimulate an inflammation in gingival tissue. The increase of GCF volume is an indication of inflammation and subsequent clinical signs of gingivitis. ${ }^{26}$ Studies show that plaque increases crevicular IL-1 $\beta$ and VEGF. ${ }^{14,15}$ Pathogenic bacteria in subgingival plaque cause a subepithelial infiltration by inflammatory cells, which produce and release IL-1 $\beta$, thus an IL-1 $\beta$ concentration in GCF increases in periodontal tissue with gingivitis or periodontitis. ${ }^{15}$ VEGF is increased by gingival fibroblasts in response to vesicle and outer membrane protein from periodontopathic bacteria. ${ }^{16}$ In our study, it was found that total amounts of IL-1 $\beta$ and VEGF in GCF had a positive correlation with plaque-induced gingivitis in both groups (PI, GI). This result may indicate that oral hygiene may be one of the factors increasing IL-1 $\beta$ and VEGF in GCF that is unrelated to epilepsy.

Many systemic diseases may adversely affect oral health due to the changes in metabolism and drug use. In some studies, which support our study, it was shown that epilepsy cases have poor oral hygiene and it has been found that GI and PI scores are higher in epileptics than in healthy children. ${ }^{27,28}$

Guneri et al. investigated the VEGF concentration in GFC in patients with periodontal diseases. ${ }^{17}$ Some of these patients (group I) had diabetic diseases, while the others (group II) were healthy without any systemic diseases. The differences of VEGF levels were found statistically insignificant between the periodontally healthy sites of these two groups and the negative control group. But they found statistically significant differences between periodontally healthy and unhealthy sites of these two groups, which is similar to Booth et al. ${ }^{18}$ Guneri's study indicated that the oral situation is more important than systemic disease for GCF mediators, because the VEGF levels in GCF were not different between periodontally healthy sites of diabetic patients and the control group. ${ }^{17}$ This result indicates that oral hygiene may be one of the factors increasing VEGF that is unrelated to epilepsy.

Sandalli and Wade recorded a positive correlation between PD and GCF volume in the gingiva of 3-5 year old children. ${ }^{29}$ The correlation was more statistically significant in a gingivitis region than in healthy gingiva. Yucel et al. reported higher GCF volumes in a deep pocket compared to a shallow pocket. ${ }^{30}$ In our study, in addition, we found a positive correlation between PD and GCF volume in both groups.

In this study, we found that the children with epilepsy were more likely to have a periodontal disease than healthy children. We could not give any exact reasons that this situation may be an immune system problem caused by epilepsy or neglected oral hygiene. In our study, there was a limitation that blood specimens were not taken 
from the patients. Thus, we could not compare these biochemical parameters in serum and GCF. Further studies are needed to clarify the effect of epileptic drugs on the immune system.

If this situation is not a problem originating from the immune system, further research should be focused on why these children care less about oral hygiene than healthy children. They spend most of their lives in a hospital and constantly have to take medication. For all these reasons, oral care may be difficult and tedious for them.

\section{Conclusions}

Our study revealed that IL-1 $\beta$, an inflammation indicator, and VEGF, an angiogenesis mediator, increase in the GCF of epilepsy patients and we can say that epilepsy patients may be at risk of periodontal disease in their future lives.

Further longitudinal clinical studies are required in order to study the oral health of children with epilepsy and the probable diagnostic value of combinations of inflammatory mediators.

\section{References}

1. World Health Organisation (WHO) Atlas. Epilepsy care in the world. WHO, Geneva, 2005.

2. Pitkanen A, Sutula TP. Is epilepsy a progressive disorder? Prospects for new therapeutic approaches in temporal-lobe epilepsy. Lancet Neurol. 2002;1:173-181.

3. Modeer T, Domeij H, Anduren I, Mustafa M, Brunius G. Effect of phenytoin on the production of interleukin- 6 and interleukin- 8 in human gingival fibroblasts. J Oral Pathol Med. 2000;29:491-499.

4. Vahabi S, Salman BN, Rezazadeh F, Namdari M. Effects of cyclosporine and phenytoin on biomarker expressions in gingival fibroblasts of children and adults: An in vitro study. J Basic Clin Physiol Pharmacol. 2014;25:167-173.

5. Horowitz MC. Cytokines and estrogen in bone: Anti-osteoporotics effects. Sci. 1993;260:626-627.

6. Dagmar SP, Meley J. Interleukin-1 $\beta$ concentration of gingival crevicular fluid. J Periodontol. 1994;65:423-428.

7. Vezzani A, Moneta $D$, Richichi $C$, et al. Functional role of inflammatory cytokines and antiinflammatory molecules in seizures and epileptogenesis. Epilepsia 2002;43 Suppl. 5:30-35.

8. Allan SM, Rothwell NJ. Cytokines and acute neurodegeneration. Nat Rev Neurosci. 2001;2:734-744.

9. Murashima YL, Suzuki J, Yoshii M. Role of cytokines during epileptogenesis and in the transition from the interictal to the ictal state in the epileptic mutant EL mouse. Gene Regul Syst Bio. 2008;2:267-274.
10. Lamster IB, Grbic JT. Diagnosis of periodontal disease based on analysis of the host response. Periodontol. 2000;1995:7, 83-99.

11. Ebersole JL, Singer RE, Steffensen B, Filloon T, Kornman KS. Inflammatory mediators and immunoglobulins in GCF from healthy, gingivitis and periodontitis sites. J Periodont Res. 1993;28:543-546.

12. Sakai A, Ohshima M, Sugano N, Otsuka K, Ito K. Profiling the cytokines in gingival crevicular fluid using a cytokine antibody array. J Periodontol. 2006;77:856-864.

13. Unlu F, Guneri PG, Hekimgil M, Yesilbek B, Boyacioglu H. Expression of vascular endothelial growth factor in human periodontal tissues: Comparison of healthy and diabetic patients. J Periodontol. 2003;74:181-187.

14. Prapulla DV, Sujatha PB, Pradeep AR. Gingival crevicular fluid VEGF levels in periodontal health and disease. J Periodontol. 2007;78:1783-1787.

15. Ishihara $Y$, Nishihara T, Kuroyanagi T, et al. Gingival crevicular interleukin-1 and interleukin-1 receptor antagonist levels in periodontally healthy and diseased sites. J Periodont Res. 1997;32:524-529.

16. Suthin K, Matsushita K, Machigashira M, et al. Enhanced expression of vascular endothelial growth factor by periodontal pathogens in gingival fibroblasts. J Periodont Res. 2003;38:90-96.

17. Guneri P, Unlu F, Yesilbek B, et al. Vascular endothelial growth factor in gingival tissues and crevicular fluids of diabetic and healthy periodontal patients. J Periodontol. 2004;75:91-97.

18. Booth V, Young S, Cruchley A, Taichman NS, Paleolog E. Vascular endothelial growth factor in human periodontal disease. J Periodont Res. 1998;33:491-499.

19. Ben-Av P, Crofford LJ, Wilder RL, Hla T. Induction of vascular endothelial growth factor expression in synovial fibroblasts by prostaglandin $E$ and interleukin-1: A potential mechanism for inflammatory angiogenesis. FEBS Lett. 1995;372:83-87.

20. Silness J, Loe H. Periodontal disease in pregnancy. II. Correlation between oral hygiene and periodontal condition. Acta Odontol Scand. 1964;22:121-135.

21. Loe $H$. The Gingival Index, the Plaque Index and the Retention Index Systems. J Periodontol. 1967, 38, Suppl, 610-616.

22. Rigau V, Morin M, Rousset MC, et al. Angiogenesis is associated with blood-brain barrier permeability in temporal lobe epilepsy. Brain 2007;130:1942-1956.

23. Kim JE, Choi HC, Song HK, et al. Levetiracetam inhibits interleukin-1 beta inflammatory responses in the hippocampus and piriform cortex of epileptic rats. Neurosci Lett. 2010;471:94-99.

24. Higuchi S, Yano A, Takai S, et al. Metabolic activation and inflammation reactions involved in carbamazepine-induced liver injury. Toxicolog Sci. 2012;130:4-16.

25. Polverini PJ. The pathophysiology of angiogenesis. Crit Rev Oral Biol Med. 1995;6:230-247.

26. Loe $\mathrm{H}, \mathrm{Holm}$-Pedersen P. Absence and presence of fluid from normal and inflamed gingivae. Periodont. 1965;149:171-177.

27. Gurbuz T, Tan H. Oral health status in epileptic children. Pediatr Internat. 2010;52:279-283.

28. Tan H, Gurbuz T, Dagsuyu IM. Gingival enlargement in children treated with antiepileptics. J Child Neurol. 2004;19:958-963.

29. Sandalli $P$, Wade AB. Crevicular fluid flow in young children. J Periodontol. 1971, 42, 713-716.

30. Yucel OO, Berker E, Gariboglu S, Otlu H. Interleukin-11, interleukin1 beta, interleukin-12 and the pathogenesis of inflammatory periodontal diseases. J Clin Periodontol. 2008, 35, 365-370. 